\title{
Regulatory Capital and Social Trade-Offs in Planning of Smart Distribution Networks with Application to Demand Response Solutions
}

DOI:

10.1016/j.epsr.2016.07.001

\section{Document Version}

Accepted author manuscript

Link to publication record in Manchester Research Explorer

Citation for published version (APA):

Martinez-Cesena, E., Turnham, V., \& Mancarella, P. (2016). Regulatory Capital and Social Trade-Offs in Planning of Smart Distribution Networks with Application to Demand Response Solutions. Electric Power Systems

Research, 141. https://doi.org/10.1016/j.epsr.2016.07.001

\section{Published in:}

Electric Power Systems Research

\section{Citing this paper}

Please note that where the full-text provided on Manchester Research Explorer is the Author Accepted Manuscript or Proof version this may differ from the final Published version. If citing, it is advised that you check and use the publisher's definitive version.

\section{General rights}

Copyright and moral rights for the publications made accessible in the Research Explorer are retained by the authors and/or other copyright owners and it is a condition of accessing publications that users recognise and abide by the legal requirements associated with these rights.

\section{Takedown policy}

If you believe that this document breaches copyright please refer to the University of Manchester's Takedown Procedures [http://man.ac.uk/04Y6Bo] or contact uml.scholarlycommunications@manchester.ac.uk providing relevant details, so we can investigate your claim.

\section{OPEN ACCESS}




\title{
Regulatory Capital and Social Trade-Offs in Planning of Smart Distribution Networks with Application to Demand Response Solutions
}

\author{
Eduardo A. Martínez Ceseña ${ }^{1}$, Victoria Turnham ${ }^{2}$, and Pierluigi Mancarella ${ }^{1}$ \\ ${ }^{1}$ School of Electrical \& Electronic Engineering, The University of Manchester, Manchester \\ M13 9PL, UK \\ ${ }^{2}$ Electricity North West Limited, Warrington WA3 6XG, UK \\ *Eduardo.MartinezCesena@Manchester.ac.uk, +44 (0) 1613064807
}

\section{Abstract}

Under the current UK regulatory framework for electricity distribution networks, asset upgrades are planned with the objectives of minimising both capital costs (and thus customer fees) and social costs such as those associated with carbon emissions and customer interruptions. This approach naturally results in economic trade-offs as network solutions meant to reduce social costs typically increase (sometimes significantly) capital costs, and vice versa. This can become an issue in a smart grid context where new operational solutions such as Demand Response (DR) may emerge. More specifically, even though there is a general belief that smart solutions will only provide benefits due to their potential to displace investments in costly assets (e.g., lines and substations), they may also introduce trade-offs associated with increased operational expenditure, power losses and emissions compared with networks with upgraded assets. On the other hand, the flexibility inherent in smart solutions could be used to balance the different types of costs, leading to attractive cost trade-offs if properly modelled, quantified and regulated. However, given the fundamental "non-asset" nature of DR, properly quantifying the resulting trade-offs so

\footnotetext{
* Corresponding author.
} 
as to perform a like-for-like comparison with traditional planning strategies is a grand challenge. In this light, this paper proposes a methodology to explicitly model and quantify capital and social cost trade-offs in distribution network planning, which can be incorporated into the existing regulatory framework. The results, based on real UK distribution networks, show that our proposed methodology can be used to explicitly model and regulate cost trade-offs. By doing so, it is possible to encourage more efficient levels of capital expenditure and social benefits by deploying the right mix of traditional asset-based and smart DR-based solutions.

Keywords: Demand response, investment planning, multi-criteria assessment, smart distribution networks, smart grid.

\section{INTRODUCTION}

Since the privatization of the UK's electricity sector began in 1990, the regulatory framework of distribution networks has undergone several revisions based on the constantly changing objectives and conditions of the nation and the electricity sector [1-3]. Early versions of the distribution regulation focused on reducing economic costs for customers by encouraging Distribution Network Operators (DNOs ${ }^{2}$ ) to make cost-effective investments and gradually reduce their capital expenditure and customer charges. Later, emerging environmental concerns and increasing dependence on electricity emphasized the

\footnotetext{
${ }^{2}$ DNOs own, operate and upgrade the electricity distribution networks.
} 
importance of different social ${ }^{3}$ costs associated with the distribution network such as electricity supply reliability, carbon emissions, and electrical power losses ${ }^{4}$.

This change in regulation is introducing trade-offs between capital and social costs, as additional capital expenditure may be necessary to design distribution networks that facilitate the mitigation of social costs. Furthermore, in the last few years, it has been recognised that mitigating social cost while maintaining relatively low capital expenditure at the distribution level is a grand challenge under business-as-usual practices, particularly in the light of an increased penetration of renewable energies distributed throughout the distribution network, the electrification of heating [4], and so forth. Accordingly, the latest versions of the regulatory framework of the electricity industry have been aiming at encouraging the development of new and smart solutions that typically rely on the active participation of customers in the management of the system via Demand Response (DR) as a means to mitigate both social and capital costs $[5,6]$.

The new "Revenue $=$ Incentives + Innovation + Outputs" $($ RIIO) network regulation model (from April 2015 to March 2023) [7,8] aims at regulating the revenues accrued by DNOs to incentivise the development of innovative and smart solutions, which may facilitate meeting desirable outputs (e.g., target levels of capital expenditure and social costs mitigation). Based on this principle, the UK regulator, namely the Office of gas and electricity markets (Ofgem), is introducing a Cost Benefit Analysis (CBA) framework

\footnotetext{
${ }^{3}$ Social costs are defined based on the regulation in place (Ofgem, 2013a) and may also include risk of injury and environmental impacts of using particular types of oils for the transformers, which are not considered in this work as they are not relevant to the DR solutions considered in this work.

${ }^{4}$ It is worth noting that power losses have well-defined capital impacts and, thus, may be considered capital costs under the regulatory framework of other countries.
} 
(hereafter named "Ofgem's CBA") to plan and assess distribution network upgrades as a part of the first RIIO regulation for electricity distribution (RIIO - ED1) [9-11].

Ofgem's CBA framework provides a means for DNOs to plan investments at the distribution level that are attractive in terms of their combined capital and social ${ }^{5}$ costs, and to negotiate (with Ofgem) proper distribution fees that would allow them to recover their capital costs. The combination of both capital and social costs (as recommended by Ofgem's CBA) implicitly introduces trade-offs, as network upgrade solutions meant to mitigate social costs typically result in increased capital expenditure, and vice versa. For instance, in order to reduce capital costs, the networks can be operated closer to margins to avoid investments in spare capacity, whereas additional capital expenditure in spare capacity may be recommended when carbon emissions and power losses (i.e., social costs) are internalised $[12,13]$. The CBA imposes a preferred level of trade-offs by assigning fixed economic values to emissions, reliability and other social aspects, which inherently undermines the case specific nature of trade-offs. Such an approach may be reasonable under traditional asset-based network reinforcement practices (e.g., based on line and substation upgrades) where large asset costs provide little flexibility for significant tradeoffs between capital and social costs to emerge. However, this may not be the case in the face of emerging and highly flexible smart solutions (e.g., DR-based solutions) which, without explicit quantification and regulation of trade-offs, can result in inefficient investments in network solutions that result in no social benefits or significant capital expenditure. Accordingly, and given the fundamentally different "non-asset" nature of flexible solutions such as DR, a new framework that models trade-offs between asset and

\footnotetext{
${ }^{5}$ The mechanism used in Ofgem's CBA to internalise social costs is described in detail in Section 3.
} 
non-asset based solutions and thus also allows a like-for-like comparison with traditional planning models is needed.

The trend to update distribution network regulation to include social costs can be observed in other countries where, as recommended by the RIIO regulation, economic prices are assigned to the components of social costs (e.g., Finland, the Netherlands, Norway, Romania and Spain [14,15]). Similarly, the importance of smart grid technologies as a means to modernise the network and provide vital economic and social benefits is widely recognised [16]. Even though these smart solutions are generally deemed highly beneficial due to their potential to defer or avoid costly investments in capital intensive assets, they can also lead to additional cost trade-offs associated with higher operational costs (e.g., DR payments) and increased power losses and emissions compared with traditional networks with upgraded lines and substations [17]. Regardless, the flexibility inherent in the smart solutions can, in principle, be used to balance the trade-offs if properly quantified and regulated. Accordingly, it is clear that existing regulation needs to be fully reviewed to recognise the new challenges faced by DNOs [18]. In fact, even though (i) regulation is aiming at integrating social costs in distribution planning (as highlighted above) and (ii) it is becoming apparent that the introduction of smart solutions can lead to significant trade-offs between capital and social costs relevant to distribution networks investments [19-21], to the best of the authors' knowledge, an approach to quantify and regulate these trade-offs has yet to be investigated.

In light of the above, the main contribution of this paper is the proposal of a methodology to enhance Ofgem's CBA (or other regulatory frameworks) by providing it with a mechanism to explicitly quantify and regulate trade-offs between capital and social 
costs associated with business-as-usual and emerging smart network upgrade solutions (taking DR-based solutions as an example). More specifically, the business-as-usual practices are represented by traditional line and substation reinforcements. The smart solutions are represented by a new DR-based method that is currently under trial in the UK and that emerged due to regulatory support to facilitate innovation (i.e., the low carbon network fund [22]), namely the Capacity to Customers $\left(\mathrm{C}_{2} \mathrm{C}\right)$ method [23]. The proposed methodology is used to assess cost trade-offs in 36 real distribution networks subject to different traditional and smart planning strategies. The results highlight that significant trade-offs between capital and social costs can emerge when smart solution become available and how their explicit assessment can provide a consistent means to compare, assess and plan distribution networks.

The rest of the paper is structured as follows. An overview of traditional and emerging (smart) distribution network planning practices is presented. In Section 3, the proposed methodology is introduced, while its application and potential to quantify and facilitate the regulation of capital and social costs are illustrated with several real case studies in Section 4. The main conclusions of this work are presented in Section 5.

\section{DISTRIBUTION NETWORK PLANNING PRACTICES}

\subsection{Traditional practices}

In the UK, medium voltage $\left(6.6 \mathrm{kV}\right.$ or $\left.11 \mathrm{kV}^{6}\right)$ distribution networks have been traditionally planned and operated based on preventive security criteria, currently dictated by the P2/6 engineering recommendations. Accordingly, UK distribution networks must be

\footnotetext{
${ }^{6}$ In the UK, medium voltage $6.6 \mathrm{kV}$ and $11 \mathrm{kV}$ networks are conventionally indicated as High Voltage (HV).
} 
redundant to facilitate the restoration of electricity supply to customers within a reasonable time frame after a credible contingency occurs ${ }^{7}$. Following these business-as-usual practices, typically two or more radial distribution feeders are interconnected through Normally Open Points (NOPs) creating open rings (see Figure 1a). If a contingency were to occur in one of the radial feeders, all customers in that feeder would momentarily lose electricity supply (see Figure 1b) while the contingency is isolated by the protection devises, typically within 3 minutes (see Figure 1c). Afterwards, electricity supply would be restored to customers not directly connected to the fault by connecting them to a neighbouring feeder after manually closing the NOP, which normally takes an hour (see Figure 1d). Finally, electricity supply would be restored to the customers directly connected to the fault by a repair crew who would manually isolate these customers from the fault and reconnect them to the network or to a mobile electricity generator while the fault is cleared.

\footnotetext{
${ }^{7}$ Network reliability is regulated in terms of interruptions that last longer than 3 minutes.
} 


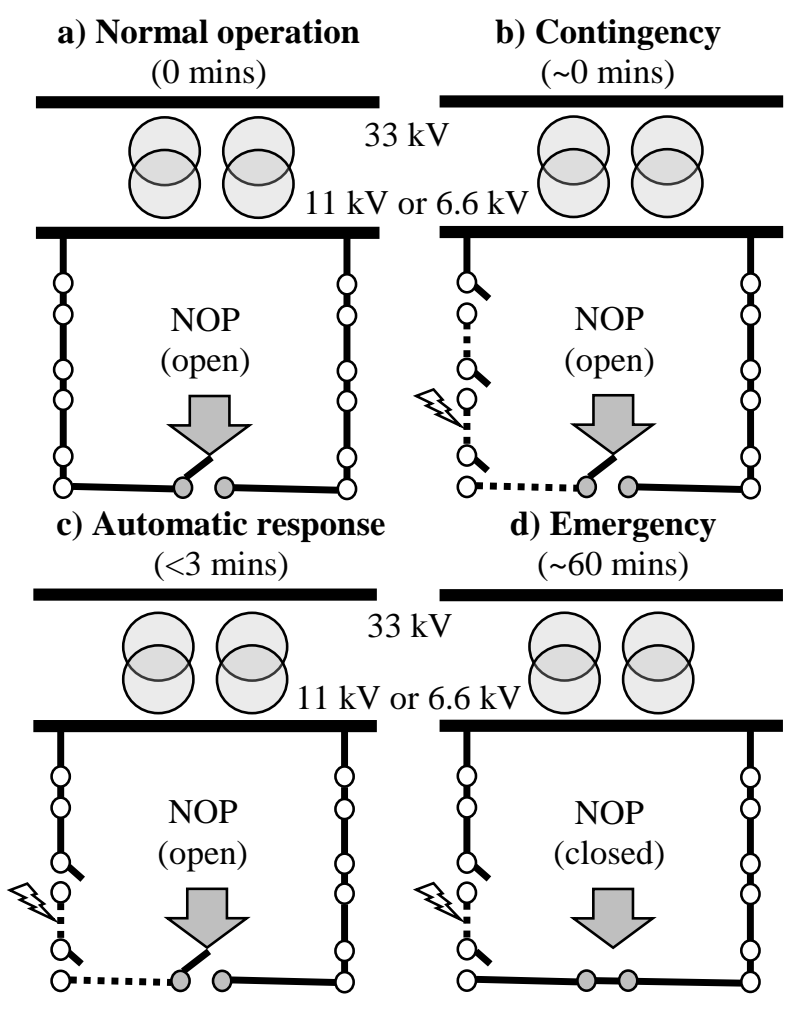

Figure 1: Business-as-usual high voltage network restoration in the UK

In order for the business-as-usual distribution network planning strategy to work, large capital investments are needed to significantly oversize each feeder so that enough spare emergency capacity is available to supply its own load as well as customers in neighbouring feeders. However, the spare emergency capacity is seldom used as the frequency of contingencies is relatively low. More specifically, on average a contingency is expected every three years, and there are several networks where contingencies have never been registered [23]. Therefore, on the one hand it would be economically attractive to avoid investing in additional emergency capacity in some networks, as it is seldom or never needed. On the other hand, without the emergency capacity, customers may be exposed to infrequent but theoretically long interruptions. Accordingly, the investments in spare 
emergency capacity could only be averted with a solution that protected customers from lengthy interruptions.

\subsection{Emerging smart practices - The $\mathrm{C}_{2} \mathrm{C}$ method}

After assessing the drawbacks of business-as-usual planning practices and reviewing new smart solutions at the distribution level [24-26], Electricity North West Limited (ENWL) proposed the $\mathrm{C}_{2} \mathrm{C}$ method in 2011 as a combination of smart grid solutions that may bring about significant capital savings in terms of avoided investments in emergency capacity as well as social savings in terms of reduced customer interruptions, power losses and carbon emissions $[23,27]$. In order to achieve this, the $\mathrm{C}_{2} \mathrm{C}$ method includes three smart solutions as described below:

1. Network reconfiguration: The NOP is operated normally closed during normal operations creating a closed ring (see Figure 2a). This is expected to result in immediate social benefits in terms of reduced electricity losses and the associated carbon emissions in most cases.

2. Network automation: The NOP and strategic location in each feeder are automated to facilitate rapid and automatic network restoration after contingencies occur. This is expected to reduce customer interruptions for more than 3 minutes, which are the only interruptions considered by UK regulation as part of social costs at present [28]. In fact, the ring configuration would normally expose more customers to interruptions, as customers in both feeders would be affected by contingencies in either feeder (see Figure 2b). However, the increased automation levels allow the network to be operated as a ring while still reducing interruptions for longer than 3 minutes (see Figure $2 \mathrm{c}$ ). 
Flexible customers providing DR services may also be reconnected within 3 minutes if the network does not require additional post-contingency capacity, such as when the contingency occurs during off-peak periods. Otherwise, DR customers may remain disconnected while network demand naturally decreases (see Figure 2d). This has been corroborated by $\mathrm{C}_{2} \mathrm{C}$ customer trials to date.

3. Post-contingency DR deployment: DR can be deployed after a contingency occurs to reduce the demand in the network during emergencies. Consequently, part (or all) the emergency capacity put in place for security reasons would not be required. As a result, due to the availability of post-contingency DR, new investments in spare security capacity can be deferred or even avoided.

These solutions provide flexibility to modify trade-offs between capital and social costs by, for example: (i) deploying DR to postpone costly network reinforcements at the expense of increasing losses and emissions, which would have been reduced due to the reinforcement; and (ii) automating the network before requiring additional network capacity, which would increase capital costs associated with automation while improving system reliability and so forth.

The $\mathrm{C}_{2} \mathrm{C}$ method is currently under trial in the UK and monitored in detail in 36 distribution networks (results from these networks are presented in this study). In this work, the $\mathrm{C}_{2} \mathrm{C}$ method is selected to represent smart network solutions, whereas traditional business as usual practices are represented with line and substation reinforcements. 
a) Normal operation

b) Contingency

(0 mins)

( 0 mins)

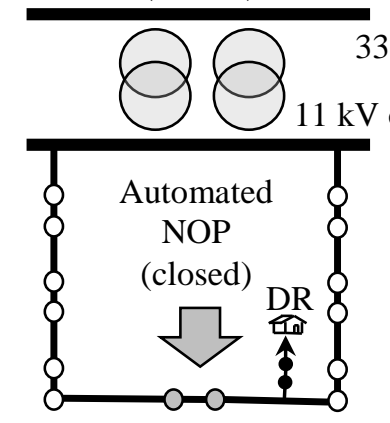

c) Automatic response
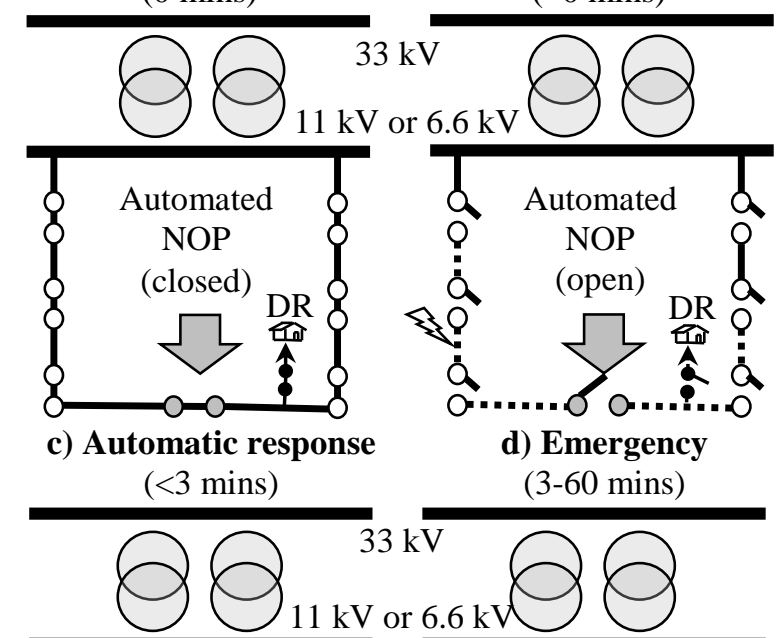

d) Emergency

(3-60 mins)

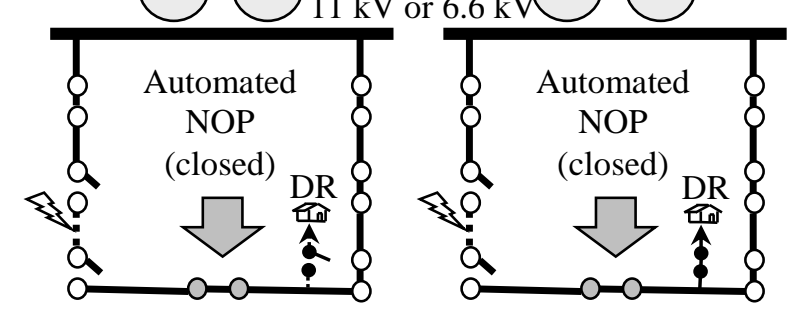

Figure 2: Smart $\left(\mathrm{C}_{2} \mathrm{C}\right.$ based) high voltage network restoration process

\section{MATERIAL AND METHODS}

As part of the new RIIO-ED1 price control in the UK, Ofgem has introduced a new CBA for the assessment of distribution network interventions. The CBA quantifies capital costs and also internalises social costs such as those associated with power losses, carbon emissions and reliability (calculated using power flow simulations, Monte Carlo analyses and other methods). However, social costs are internalised without explicitly quantifying the impacts that social costs mitigation can have on capital expenditure in particular conditions, and vice versa. As a result, the CBA framework may be biased to encourage 
significant capital expenditure or little social benefits in some cases by incentivising or hampering the deployment of particular solutions (e.g., smart DR based solutions).

Based on the above, a methodology to extend Ofgem's CBA to assess cost tradeoffs is proposed in this work. The proposed tool provides explicit metrics of capital expenditure, social costs and trade-offs. This can be used to provide a coherent comparison of traditional and smart solutions and, ultimately, assess and regulate assets built at the distribution level.

\subsection{Ofgem's CBA}

Based on the CBA formulation proposed by Ofgem, the total capital costs $\left(\mathrm{Cdno}_{y}\right)$ incurred by DNOs when investing in one of the $\mathrm{n}$-th available network upgrade solutions $\left(I_{n, y}\right)$ in a given year $(y)$ is the summation of (i) the expensed investment $\left(\operatorname{Iexp}_{y}\right)$, which is a part of the investments that can be recovered immediately; (ii) depreciation (Dep $)$, which is a part of the capitalized investment (Icap $)_{y}$ that can be recovered over time divided by a depreciation lifetime ( $T$ dep) assumed to be 45 years; and (iii) the cost of capital $\left(C C_{y}\right)$, which is a profit margin based on the regulated asset value $R A V_{y}$ and the pretax Weighted Average Cost of Capital (WACC). This procedure is summarized by (1) - (5) [9]. It is worth noting that similar CBA frameworks could be found in other countries where specific economic prices and factors (e.g., discount rates, planning horizons, capitalised ration, and so forth) are considering for different capital and social terms. The proposed approach can also be applied with these CBA frameworks as long as at least one social factor is considered. 


$$
\begin{gathered}
C d n o_{y}=I \exp _{y}+\operatorname{Dep}_{y}+C C_{y} \\
I \exp _{y}=0.15 \times \sum_{n=1} I_{n, y} \\
D e p_{y}=\sum_{y 1=1}^{y} \frac{I c a p_{y 1}}{T d e p} \\
C C_{y}=R A V_{y} \times W A C C \\
I c a p_{y}=0.85 \times \sum_{n} I_{n, y} \\
R A V_{y}=I_{C a p_{y}}-\operatorname{Dep}_{y}-R A V_{y-1}
\end{gathered}
$$

Also, as defined by Ofgem, the total social costs $\left(C_{s o c_{t}}\right)$ associated with a particular network upgrade solution are calculated from (7) as the sum of costs associated with losses $\left(\operatorname{Closs}_{t}\right)$, emissions $\left(C \mathrm{Co} 2_{t}\right)$, customer interruptions $\left(C c i_{t}\right)$ and customer minutes lost $\left(\mathrm{Ccml}_{t}\right)$. These parameters are estimated based on relevant studies such as power flow simulations, probabilistic reliability studies and so forth [29].

$$
\operatorname{Csoc}_{t}=\operatorname{Closs}_{t}+\operatorname{Cco2}_{t}+\mathrm{Cci}_{t}+\mathrm{Ccml}_{t}
$$

Finally, the annual capital and social costs are discounted (discount rates $(d)$ of $3.5 \%$ and $3 \%$ are used for cash flows within 30 years and between 31 and 45 years in the future, respectively) to produce capital $\left(N P C_{C}\right)$, social $\left(N P C_{S}\right)$ and combined capital and social $\left(N P C_{C+S}\right)$ costs metrics presented in (8), (9) and (10), respectively (Ofgem, 2013a). The combined capital and social costs metrics $\left(N P C_{C+S}\right)$ are used by DNOs to plan relevant network upgrades and justify the relevant capital expenditure metrics $\left(N P C_{C}\right)$ that are used to negotiate with Ofgem adequate network fees to recover their costs. 


$$
\begin{aligned}
& N P C_{C}=\sum_{t=1} \frac{D N O_{-} \operatorname{costs}_{t}}{(1+d)^{t}} \\
& N P C_{S}=\sum_{t=1} \frac{\text { Social_costs }_{t}}{(1+d)^{t}} \\
& N P C_{C+S}=N P C_{C}+N P C_{S}
\end{aligned}
$$

In practice, DNOs may maximise their benefits subject to a given price control if investment decisions would be based on the $N P C_{C}$ criterion. This would potentially lead to reductions in capital expenditure (and eventually to lower customer charges) at the expense of increasing social costs (sometimes significantly) at the distribution level. However, distribution network upgrades should be justified to Ofgem in terms of the $N P C_{C+S}$ criterion, which can lead social costs mitigation as well as to significantly higher capital expenditure in some conditions.

Considering the objectives set by the new RIIO-ED1 regulation, it is attractive to deploy solutions (e.g., traditional or smart DR based solutions) that facilitate social costs mitigations without substantially increasing capital expenditure. This could be achieved by extending Ofgem's CBA with a mechanism to explicitly assess and regulate trade-offs between capital and social costs, as the one proposed in this work and described below.

\subsection{Proposed methodology}

The assessment of trade-offs between multiple objectives is a well-studied topic in the area of decision planning, particularly multi-criteria and multi-objective planning [30]. 
Generally speaking, the most typically used techniques to address trade-offs are based on either weights or constraints. The former involves using weights to redefine the value of different types of social costs, which may be unattractive for regulatory applications as the $N P C_{S}$ and $N P C_{C}$ would be redefined for each study based on relevant weights. The latter involves using constraints to redefine the strategies to deploy different interventions (e.g., the $\mathrm{C}_{2} \mathrm{C}$ method, and line and substation reinforcements), and would not affect the current definitions of the $N P C_{C}$ or $N P C_{S}$. Even though both approaches could be used for this study, the constraints method is selected in this work due to the added complexity associated with weighting method.

Based on the above, the trade-offs between capital and social costs are modelled below by constraining additional capital expenditure. That is, sets of investment strategies ${ }^{8}$ that result in different combinations of social and capital costs are defined by constraining maximum capital expenditure. Such an approach would require the DNOs to produce several investment strategies to be assessed by the tool, which is also required by the current version of Ofgem's CBA to justify the selection of a given strategy. A high level description of this process is presented in Figure 3. The process begins by defining potential network upgrade solutions, such as traditional line and substation upgrades and smart DR based solutions (e.g., the $\mathrm{C}_{2} \mathrm{C}$ method in this study). Afterwards, the application of each solution in different years of the planning horizon (45 years according to Ofgem's CBA) may be recommended based on technical, economic or social considerations. Finally,

\footnotetext{
${ }^{8}$ An investment strategy is a set of investment alternatives recommended for a certain demand growth scenario. For example, in a scenario where demand is expected to grow by $1 \%$ each year, a strategy could be to deploy DR (e.g., in year 3 ) to increase network headroom and reinforce the distribution network later on (e.g., in year 8) if demand continues to grow at the given rate.
} 
investment strategies specifying the use of the aforementioned solutions in particular years (based on one or more demand growth scenarios) would be selected based on their expected performance in terms of $N P C_{C+S}, N P C_{C}$ and $N P C_{S}$.

The use of the manual process shown in Figure 3 for research purposes can be cumbersome. Thus, in this work, the process is automated using an optimisation approach. The advantages of using an optimisation engine are that it provides systematic, comprehensive and replicable means to assess all available network upgrade solutions. The engine is based on exhaustive searches to assess all feasible interventions that could be deployed and select the best strategy. See [31-33] for a more technical and detailed description of the optimisation engine.

Based on the above, the methodology proposed in this work combines capital expenditure constraints and an optimisation engine ${ }^{9}$ to provide Ofgem's CBA with a mechanism to assess and regulate trade-offs between capital and social costs. A high level description of the proposed methodology is presented in Figure 4.

\footnotetext{
${ }^{9}$ The optimisation engine can be replaced by the series of studies that DNOs would normally do to comply with Ofgem's CBA and which are represented in Figure 3.
} 


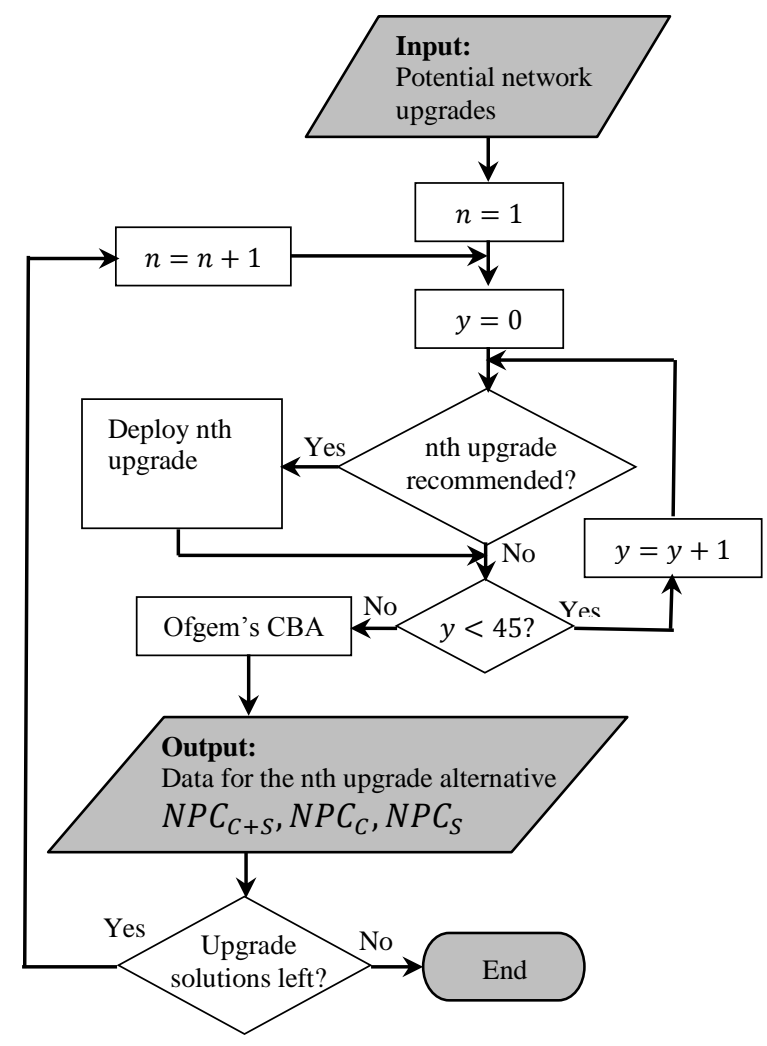

Figure 3: High level description of the traditional formulation of distribution network upgrade planning practices 


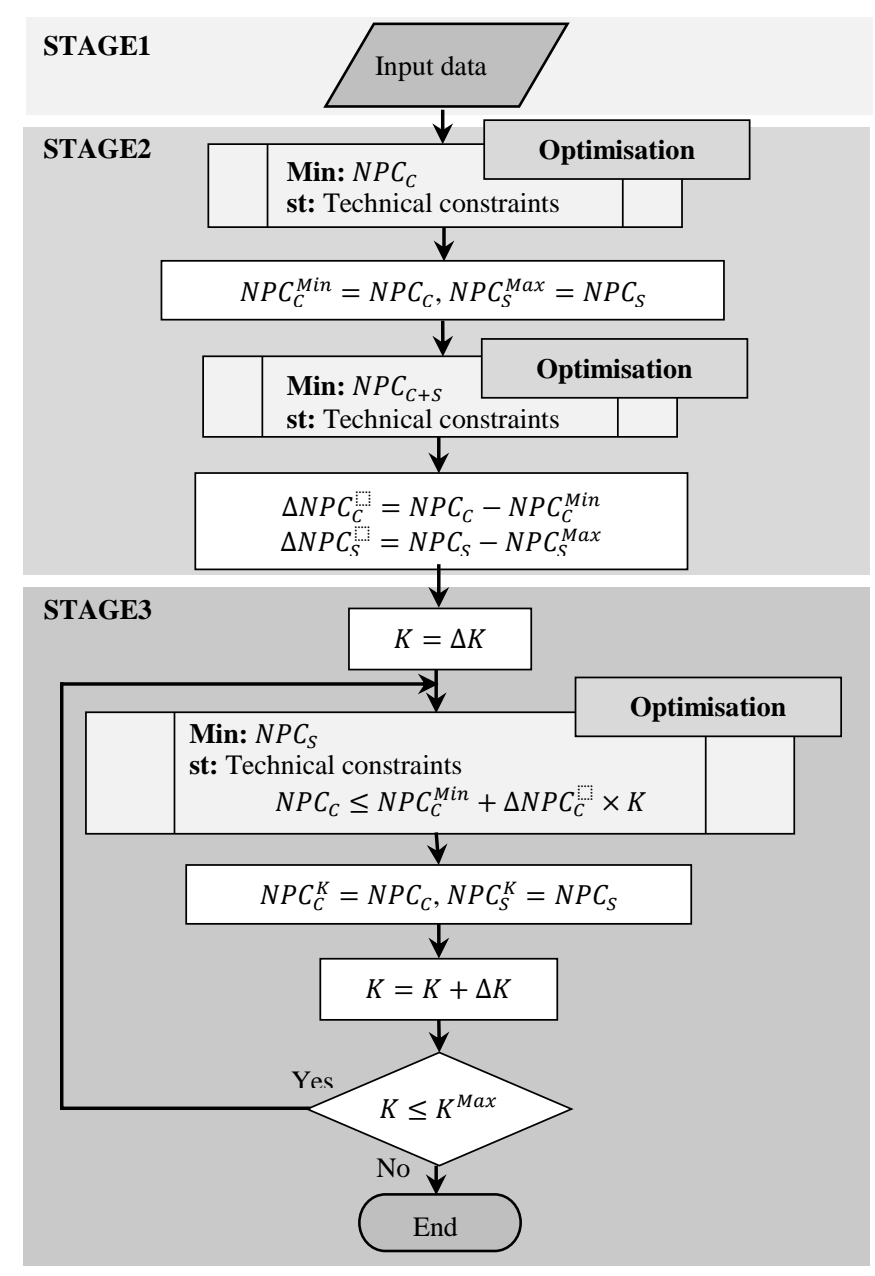

Figure 4: High level flow diagram of the proposed methodology

At stage 1, all the inputs required by Ofgem's CBA are collected, as is normally done for distribution network reinforcement planning practices. This information includes a description of all investment strategies considered (e.g., combinations of the $\mathrm{C}_{2} \mathrm{C}$ method and line and substation reinforcements) in terms of the associated initial and periodic capital expenditure, power losses and emissions (from AC power flows, and emission factors provided by Ofgem), customer interruptions and minutes lost estimated using sequential Monte Carlo simulation (see $[29,34]$ ), and so forth. This information has to be 
forecasted on an annual basis for 45 years (currently from 2015) based on a best-view forecasts of expected demand growth in the distribution network. See $[9,35]$ for a detailed description of the different inputs required to populate Ofgem's CBA, as well as relevant emissions and costs factors.

At stage 2, the extreme trade-offs associated with internalising social costs instead of only minimising capital expenditure are identified. For this purpose, a two stages process is used. Firstly, an investment strategy that only minimises capital costs is identified by using the $N P C_{C}$ criterion denoted by (8) as the objective function for the optimisation engine. The result of this process is the strategy with the lowest capital costs $\left(N P C_{C}^{M i n}\right)$ and the highest social costs $\left(N P C_{S}^{M a x}\right)$. Secondly, a new investment strategy is formulated with the objective of minimising total costs (i.e., $N P C_{C+S}$ ). As a reduction of social costs typically leads to additional capital costs, this strategy will lead to $\triangle N P C_{C}$ higher capital costs and $\triangle N P C_{S}\left(\triangle N P C_{S}\right.$ is negative) lower social costs compared with the previous strategy (i.e., strategy based on $N P C_{C}$ minimisation). These extreme cost tradeoffs are represented by (11). It is important to note that, strictly speaking, a multi-objective framework should consider the minimisation of $N P C_{S}$. However, this would result in a highly costly strategy where all solutions would be implemented immediately (as oversizing the network and substation, as well as increasing automation levels provide social benefits), which can be deemed unrealistic.

$$
N P C_{C+S}=N P C_{C}^{M i n}+\triangle N P C_{C}+N P C_{S}^{M a x}+\triangle N P C_{S}
$$

This approach provides a clear quantification (in economic terms) of the trade-offs introduced by Ofgem's CBA. Clearly, if the extreme cost trade-offs are not significant, the 
rest of the methodology could be neglected (this may be the case in the absence of smart solutions). Conversely, if the trade-offs are significant, other combinations of capital and social costs (e.g., providing most social benefits at a fraction of the capital expenditure) can be explored based on the third stage of the methodology.

At stage 3, a straightforward approach based on a specified constant (constant $\mathrm{K}$ ) is used to identify alternative investment strategies that offer different combinations of capital and social costs. For this purpose, new investment strategies are formulated by constraining maximum capital costs with (12) and using the optimisation engine to formulate strategies that minimise social costs (i.e., $N P C_{S}$ ). Different cost trade-offs can be produced by varying the constant $K$ between zero and one, which result in minimum capital and social costs (within the context of Ofgem's CBA), respectively.

$$
N P C_{C} \leq N P C_{C}^{M i n}+\triangle N P C_{C} \times K
$$

It is important to note that, by introducing the $\mathrm{K}$ factor to change the trade-offs recommended by Ofgem's CBA, a distinction between the value of capital and social costs is introduced. This distinction is not meant to imply that either the capital or social costs are more valuable, but to recognise the different nature of the costs. More specifically, capital costs are strictly associated with clear economic signals (e.g., based on capital expenditure), whereas social costs are valued using economic prices that may be estimated based on financial benefits (e.g., financial value assigned to carbon savings and reliability improvements). The estimated economic prices assigned to social costs by the regulator may be reasonable for distribution network planning when the potential for costs trade-offs is low (e.g., under traditional conditions where only significant social savings sufficient to 
offset the large capital costs of lines and substations upgrades would be pursued). However, as the potential for trade-offs increases (e.g., due to the emergence DR and other smart solutions that can be used independently of combined with traditional asset-based solutions to pursue different combinations of capital and social savings, see Section 2.2), the validity of the value assigned to social costs can become questionable and regulation of trade-offs (as done with factor $\mathrm{K}$ ) becomes important.

The outputs of the methodology are sets of investment strategies that lead to different cost trade-offs in the form of potential combinations of capital and social costs. This information provides new means to quantify and regulate cost trade-offs relevant to distribution network upgrades. For example, the information provided can be used to (i) select cost-effective strategies in terms of unit of social cost reduction per unit of additional capital spent (i.e., $\triangle N P C_{S} / \triangle N P C_{C}$ subject to $\triangle N P C_{C}>>0$ ), (ii) the most socially attractive strategy subject to a maximum capital expenditure allowance, (iii) the most economical strategy that provides at least the same social mitigation as business-as-usual solutions, and so forth. Some of these ideas will be further discussed and illustrated in the next section.

\section{CaSe STUdy, Results AND Discussion}

In this section, the methodology is applied to several case studies comprising 2 cases, 36 real distribution networks and 5 demand growth scenarios. The two cases considered are referred to as the Base case and the DR case. In the Base case, only traditional line and substation reinforcements are considered as network upgrade alternatives, and demand is considered passive and dictated by a demand growth scenario. This case is used as a baseline as it represents business-as-usual practices. In the DR case, 
DR and network automation and reconfiguration can be deployed as alternatives to or in combination with traditional line and substation reinforcements (as dictated by the $\mathrm{C}_{2} \mathrm{C}$ method). This case is used to represent the effects that DR based smart solutions can have at the distribution level. The distribution networks considered in this study are the 36 real networks currently being monitored and modelled in detail as part of the $\mathrm{C}_{2} \mathrm{C}$ trials [36,37]. The 5 demand growth scenarios considered were formulated by ENWL as potential bestview forecasts for demand growth in the 36 trial networks [38].

The methodology is illustrated and some preliminary conclusions are drawn using a single network and a scenario. Afterwards, the findings are expanded based on the assessment of all 36 networks in different scenarios.

\subsection{Single network assessment}

Consider the two feeders of the Clover Hill $6.6 \mathrm{kV}$ distribution network shown in Figure 5. This network is connected to a substation with a firm capacity of $20 \mathrm{MW}$ and supplies 3327 customers (mostly urban customers) with a peak demand of 4MVA. The headroom in the network and substation (based on AC power flow studies and P2/6 security considerations [39]) is currently $120 \mathrm{kVA}$ and $683 \mathrm{kVA}$, respectively. Based on information from the DNO, reinforcing the lines to increase capacity by $920 \mathrm{kVA}$ costs $67 \mathrm{k} £$ (a second line reinforcement would cost $82 \mathrm{k} £$ ), while reinforcing the substation costs $338 \mathrm{kf}$. Based on information from the $\mathrm{C}_{2} \mathrm{C}$ trials, up to two 0.47 MVA peak of DR can be procured at a cost of $23 \mathrm{k} / \mathrm{y}$ each ${ }^{10}$. Once a DR block is contracted, the relevant end-users are entitled to the annual DR payment for at least 3 years, regardless of whether or not DR

\footnotetext{
${ }^{10}$ Other DR block sizes could be considered as long as the relevant deployment costs associated with additional contracts, administrative and management fees, as well as increased DR block availability uncertainty, are quantified.
} 
capacity is required. DR capacity requirements are oversized by $10 \%$ to account for uncertainty. In addition an investment of $23 \mathrm{k} £$ in relevant network and customer automation is required.

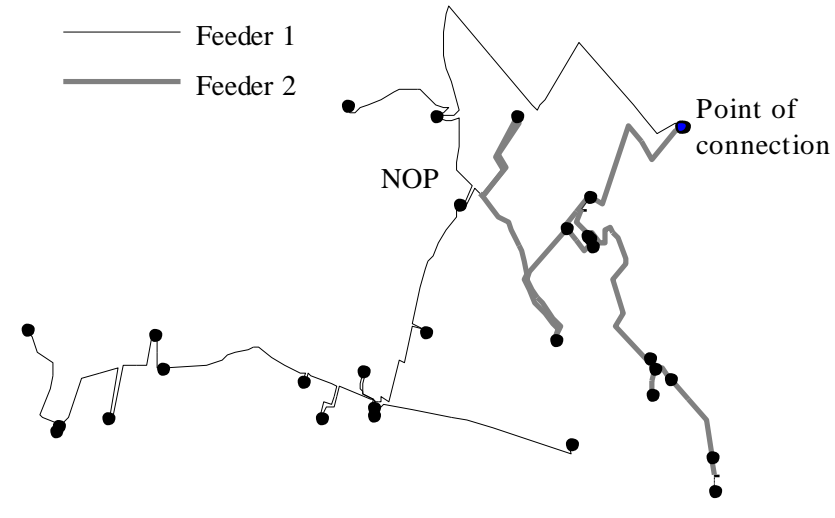

Figure 5: Clover Hill distribution network

Assume the demand growth scenario presented in Figure 6 and the Base case where only traditional line and substation reinforcements are available (this information is used to populate the methodology as part of stage 1). As part of stage 2, based on the capital costs minimisation criterion $\left(N P C_{C}\right)$, the lines should be upgraded in 4 years and once more in 17 years, whereas the substation should be reinforced in 15 years. Note that investments are proposed a few years before firm capacity is reached due to the construction lead time associated with the intervention (i.e., 2 and 3 years for line and substation reinforcements, respectively). This investment strategy results in a capital cost $\left(N P C_{C}\right)$ of $289 \mathrm{k} £$ and a social cost $\left(N P C_{S}\right)$ of $698 \mathrm{k} £$. In this case, the recommended scheme and associated capital and social costs do not change (i.e., $\triangle N P C_{C}=0$ ) even after internalising social costs based on the $N P C_{C+S}$ criterion as recommended by Ofgem's CBA framework. That is, in this 
case, business-as-usual practices under current regulation cannot facilitate social costs mitigation.

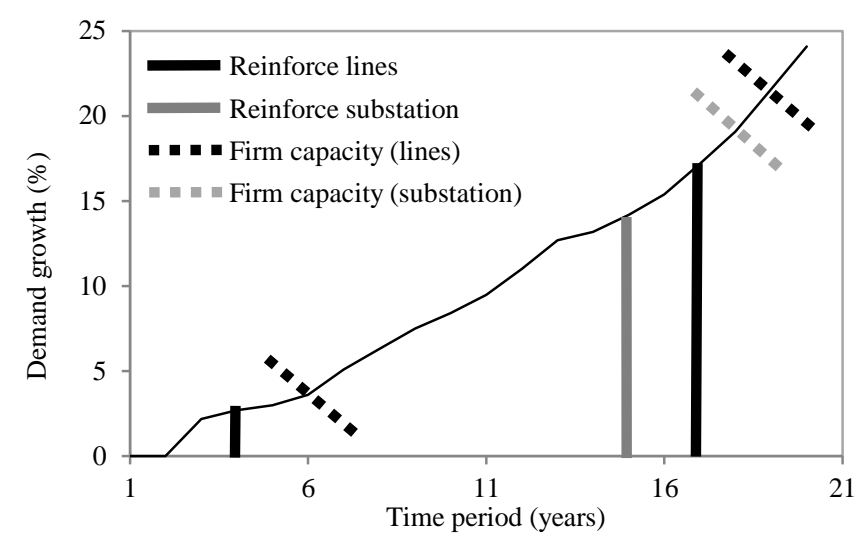

Figure 6: Investment strategy for the Clover Hill network considering the Base case, capital cost minimization and Scenario 1

Now, consider the DR case where $\mathrm{C}_{2} \mathrm{C}$ interventions can be deployed, as well as traditional line and substation reinforcements. In this case, the $N P C_{C}$ and $N P C_{C+S}$ criteria result in fundamentally different strategies. As shown in Figure 7, based on the $N P C_{C}$ criterion that neglects social costs, a $\mathrm{C}_{2} \mathrm{C}$ intervention with a lead time of a year is recommended in year 5 to defer the first line reinforcement to year 5 and avoid the second line reinforcement as well as the substation reinforcement (compared with the Base case). As a result, capital expenditure is reduced to $253 \mathrm{kf}$ compared with $289 \mathrm{k} £$ in the Base case, and social costs increase to $713 \mathrm{k} £$ compared with $698 \mathrm{k} £$ in the Base case. Based on the $N P C_{C+S}$ criterion (see Figure 8), the $\mathrm{C}_{2} \mathrm{C}$ intervention is now performed in year 1 to maximise total benefits. As a result, social costs decrease to $561 \mathrm{k} £\left(\triangle N P C_{S}=-152 \mathrm{k}\right)$ while capital costs increase to $289 \mathrm{k} £\left(\Delta N P C_{C}=36 \mathrm{kf}\right)$, which is roughly the capital costs associated with the Base case. 


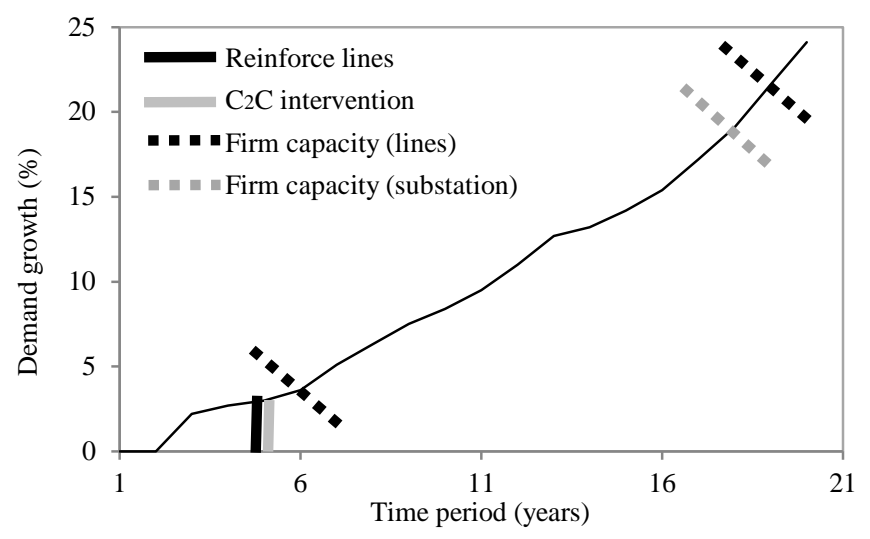

Figure 7: Investment strategy for the Clover Hill network considering the DR case, capital cost minimization and Scenario 1

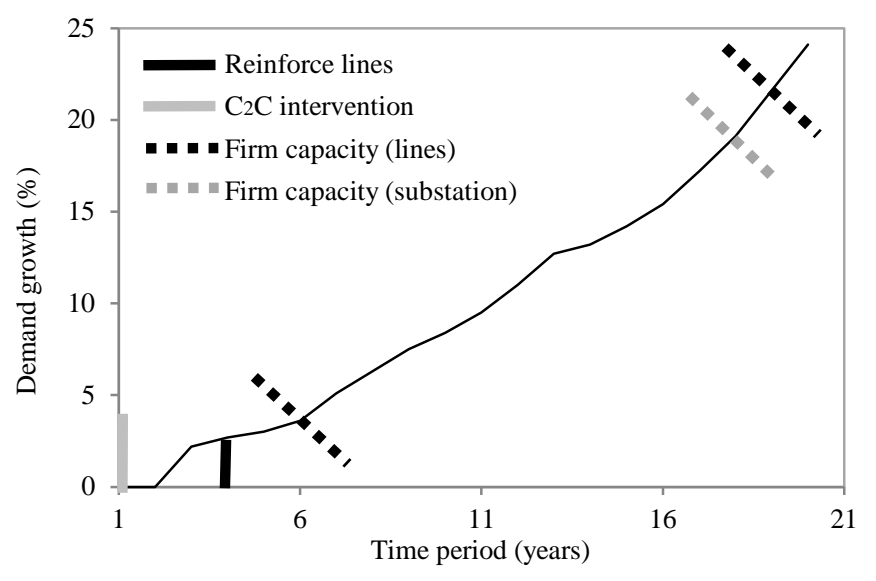

Figure 8: Investment strategy for the Clover Hill network considering the DR case, capital and social cost minimization and Scenario 1

The results so far show that the use of a smart DR based network upgrade solution has introduced attractive capital and social cost trade-offs that could lead to reduced capital expenditure and social costs compared with the base case. However, if on the one hand, DNOs were allowed to use the $\mathrm{C}_{2} \mathrm{C}$ exclusively to reduce capital costs at the distribution 
level $^{11}$ (i.e., using the $N P C_{C}$ criterion or setting $K=0 \%$ ), the social costs associated with the Clover Hill network would increase compared with those of the Base case. On the other hand, if social costs are internalised based on current regulations (i.e., using the $N P C_{C+S}$ criterion or setting $K=100 \%$ ), the DNO would not be able to reduce capital expenditure compared with the Base case. Both conditions can be deemed unattractive either from the social or economic perspectives.

Alternative network upgrade strategies that offer new combinations of capital and social costs can be defined using the rest of the methodology (stage 3). In this example, the designs are formulated by setting $K=[0 \% 25 \% 50 \% 75 \% 100 \%]$ in (12) (other values can be used). The results, presented in Figure 9 and Table 1, illustrate different trade-offs between capital and social costs associated with the Base and DR cases. Note that the Base case is not presented in the table as the relevant capital and social costs do not change in this example. Also note that, as the trade-offs are negligible for $\mathrm{K}=0 \%$ and $\mathrm{K}=25 \%$, $\triangle N P C_{S} / \triangle N P C_{C}$ is undefined and should not be calculated. In fact, it is important to note that ratio-based criteria, such as this one, may not be adequate for small values as, even though they may highlight highly effective conditions, the net benefit (magnitude) associated with those conditions can be negligible.

\footnotetext{
${ }^{11}$ The prospect of deploying DR to reduce capital expenditure in costly network reinforcements was one of the main reasons for the development of the $\mathrm{C}_{2} \mathrm{C}$ method.
} 


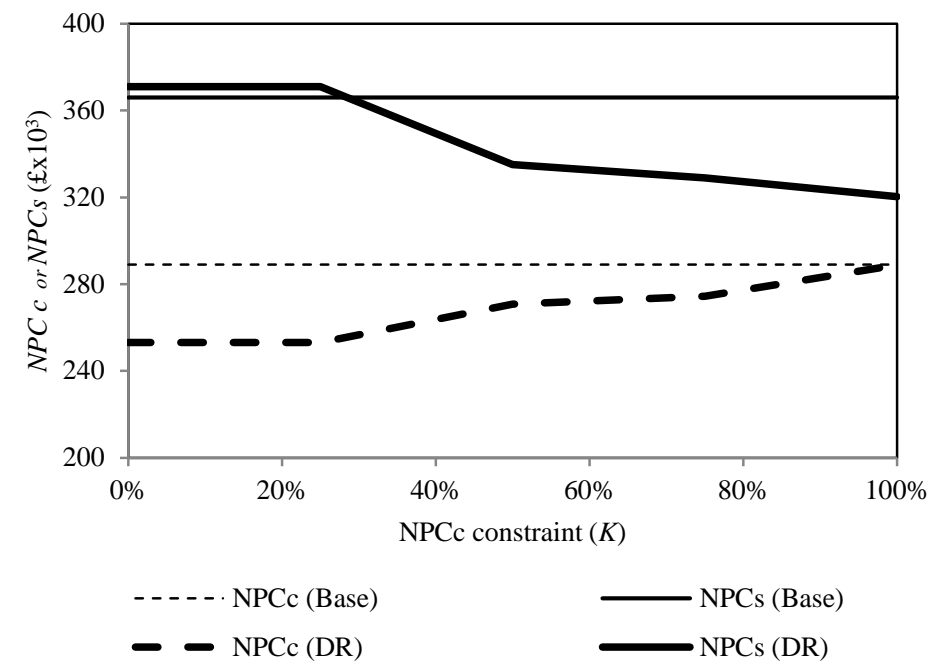

Figure 9: Capital and social costs trade-offs for the Clover Hill network considering Scenario 1 and variants of the social costs mitigation mechanism

\begin{tabular}{|c|c|c|c|}
\hline$K$ & $\begin{array}{l}\text { DR case } \\
\triangle N P C_{C}\end{array}$ & $\triangle N P C_{S}$ & $\Delta N P C_{S} / \triangle N P C_{C}$ \\
\hline $0 \%$ & $0 \mathrm{kf}$ & $0 \mathrm{k} £$ & - \\
\hline $25 \%$ & $0 \mathrm{kf}$ & $0 \mathrm{k£}$ & - \\
\hline $50 \%$ & $18 \mathrm{kf}$ & $108 \mathrm{kf}$ & 6.14 \\
\hline $75 \%$ & $21 \mathrm{kf}$ & $126 \mathrm{kf}$ & 5.95 \\
\hline $100 \%$ & $36 \mathrm{kf}$ & $153 \mathrm{kf}$ & 4.28 \\
\hline
\end{tabular}

Table 1: NPC variations associated with the DR case for the Clover Hill network

The outputs of the proposed methodology are the explicit identification of alternative network upgrade solutions that offer different cost trade-offs (as shown in Figure 9 and Table 1). This information can facilitate the identification of capital and social costs combinations that may be more attractive than those preferred from the perspective of capital expenditure and current regulation. For instance, in this example, it may be attractive to limit additional capital expenditure to $18 \mathrm{k} £(50 \%)$ to achieve a social cost reduction of $108 \mathrm{k} £$, which corresponds to $70 \%$ of the potential social costs reduction considered and 6.14 times the additional capital expenditure (i.e., the most cost effective 
solution in terms of $\triangle N P C_{S} / \triangle N P C_{C}$ subject to $\left.\triangle N P C_{C}>>0\right)$. Alternatively, other metrics can be used to regulate the cost trade-offs such as setting a maximum additional capital expenditure allowance (e.g., $K=75 \%$ ) or selecting a strategy that provides at least the same social costs mitigation as the Base case (i.e., $K=30 \%$ ). The metrics provided by the methodology can be incorporated into current regulations to facilitate more attractive combinations of capital expenditure and social costs associated with distribution network upgrades. This would allow a like-for-like comparison of emerging smart solutions with existing upgrade alternatives based on their impacts on both capital and social costs. This is a key contribution of this research work.

Based on the results presented in this example, it is possible to draw four preliminary findings as detailed below.

1. Existing network regulation tends to encourage relatively little social cost mitigation and capital expenditure increase subject to current business-as-usual practices.

2. The introduction of smart solutions (e.g., DR based solutions) may offer flexibility to achieve new combinations of capital and social costs that could facilitate attractive social and capital costs mitigation if the associated trade-offs are explicitly quantified and regulated.

3. Under the current regulatory framework, the introduction of new smart and flexible network upgrade alternatives, such as the $\mathrm{C}_{2} \mathrm{C}$ method, may facilitate significant social benefits at the expense of limiting the associated capital benefits.

4. The proposed methodology can facilitate the regulation of cost trade-offs. 


\subsection{Wider network assessment}

In this section, the case study is extended to 36 real UK distribution networks and five demand growth scenarios proposed by the relevant $\mathrm{DNO}$ [38] to elaborate and corroborate the four initial findings presented in the previous case study. Detailed descriptions of each network, including capital and social performance (without including trade-off analyses) when networks reinforcements are planned under a wide range of conditions (e.g., different objective functions, system headroom, infrastructure and DR costs, DR availability, uncertainty scenarios, and so forth) can be found in the references $[31-34,36,38]$.

The main results of the complete case study are presented in Figure 10. The figure presents the average $N P C_{S}$ and $\triangle N P C_{S}$ (solid lines), and $N P C_{C}$ and $\triangle N P C_{C}$ (dashed lines) associated with the Base case (square markers), DR case (triangle markers) and the difference between both cases (rhombus markers), subject to different capital expenditure constraints $(K)$.

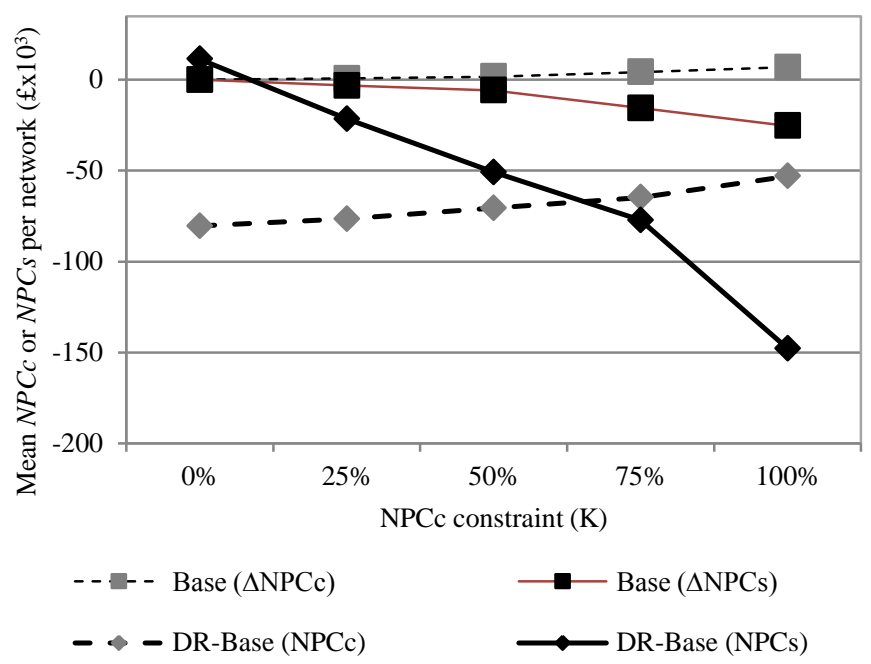

Figure 10: Comparison of the Base DR cases in terms of the $\mathrm{NPC}_{\mathrm{C}}, \mathrm{NPC}_{\mathrm{s}}, \triangle \mathrm{NPC}_{\mathrm{C}}$ and $\triangle \mathrm{NPC}_{\mathrm{S}}$ 
The first initial finding, namely the relatively little potential for social costs mitigation (but also little increase in capital expenditure) under the current regulatory framework and subject to business-as-usual practices, can be corroborated by observing the performance of the Base case (square markers) in terms of the $\triangle N P C_{C}$ and $\triangle N P C_{S}$ when $K=100 \%$. In this example, social costs are reduced in average by $25 \mathrm{kf}$ per network, whereas capital expenditure only increases by $7 \mathrm{k} £$ per network.

The second initial finding suggests that the introduction of DR based network upgrade can facilitate new potentially attractive capital and social costs combinations. This can be corroborated by comparing the costs associated with the Base and DR cases (rhombus markers). As shown, the DR case offers several combinations of capital and social costs that are lower than those of the Base case, even without fully internalising social costs as recommended by Ofgem's CBA framework. Accordingly, it would be possible to outperform the social costs mitigation potential of business-as-usual practices while still achieving significant capital benefits (e.g., grey rhombus markers at $K=50 \%$ or $75 \%)$.

However, as highlighted by the third initial finding, under current regulations the smart DR method would be deployed mostly to facilitate social costs benefits at the expense of limiting the potential of DR to reduce capital expenditure. As shown in Figure 10 , the DR intervention can facilitate an average reduction of social costs of $148 \mathrm{k} £$ per network (black rhombus marker at $K=100 \%$ ) at the expense of reducing capital savings from roughly $80 \mathrm{k} £$ (grey rhombus marker at $K=0 \%$ ) to about $50 \mathrm{k} £$ (grey rhombus 
marker at $K=100 \%$ ). This is may be unattractive for DNOs; although it can be argued that it is acceptable form a welfare perspective as total capital expenditure is still lower than that of the Base case (i.e., DNOs can still minimise capital expenditure). However, this is not always the case as shown in the case study presented in Section 5.1 where the DNO would be unable to make any capital saving. In fact, as shown in Figure $11^{12}$, there are several conditions within the scope of this study where the introduction of the smart DR intervention resulted in an increase of capital expenditure compared with the Base case (33\% of the cases), which can be of more than $50 \mathrm{k} £$ in extreme conditions. In regard to these conditions, it may be particularly attractive to expand the current distribution network regulatory framework with a mechanism to addressed cost trade-offs in specific applications as the tool presented in this work.

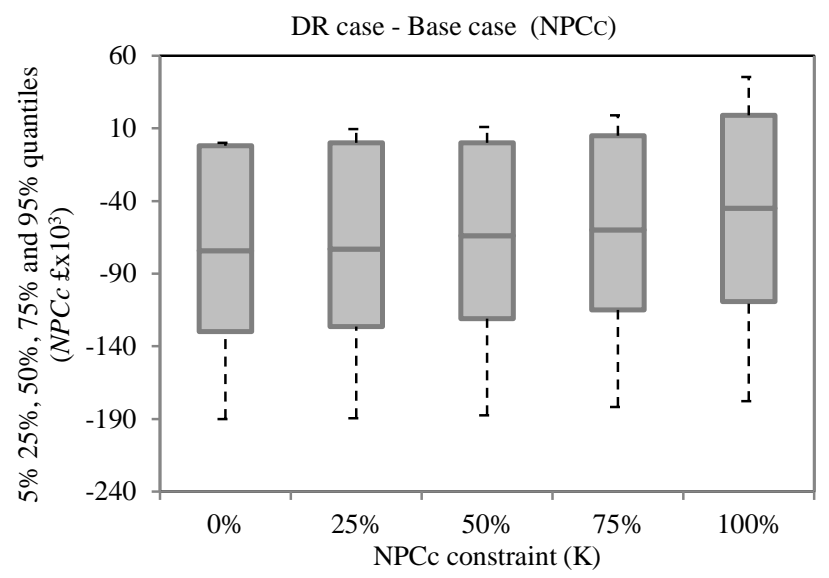

Figure 11: Comparison of $\left(\mathrm{NPC}_{\mathrm{C}}\right)$ capital costs between the DR and Base cases

As hinted by the fourth initial finding, the proposed methodology can facilitate the identification of attractive combinations of capital and social costs, and could be included

\footnotetext{
12 The figure shows the occurrence of different conditions (in terms of quantiles) where different levels of additional capital expenditure where achieved by moving from the Base to the $\mathrm{C}_{2} \mathrm{C}$ case.
} 
in the current distribution network regulatory framework. The main feature of the proposed approach is that it allows the identification of different investment alternatives that result in a variety of social costs savings subject to a maximum capital expenditure $\triangle N P C_{C}$ ). As a result, it is possible to assess different strategies with the aim of identifying the option that provides the most attractive social costs savings at the lowest capital cost. As discussed in the example, the tool can be used to identify the least cost solution that offers attractive social cost reductions that are equal to or greater than those estimated for the Base case subject to current regulations $(K=100 \%)$. This would result in limiting additional capital expenditure to $25 \%$ under most conditions considered within this study. Alternatively, the tool can be used to find the most efficient cost trade-off in terms of $\triangle N P C_{S} / \triangle N P C_{C}$ subject to $\triangle N P C_{C} \gg>0$ (see Figure 12), which can be achieved under most conditions under consideration by limiting additional capital expenditure to $50 \%$. Ultimately, the expenditure and social cost reduction targets and trade-offs would be selected by policy makers based on national targets and/or political reasons, and the use of a methodology to quantify these cost trade-offs would be required to address the particular characteristics of specific networks.

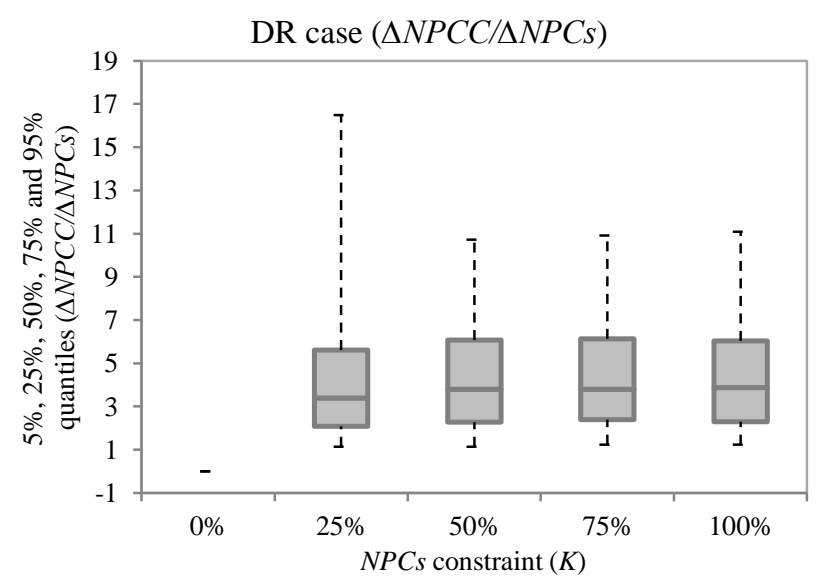




\section{Figure 12: Capital and social cost trade-offs $(\triangle \mathrm{NPCs} / \triangle \mathrm{NPCc})$ associated with the DR case}

\section{CONCLUSION}

This paper proposed a new methodology to explicitly evaluate trade-offs between capital and social costs associated with distribution network planning alternatives, particularly when smart solutions such as DR are considered. As shown, conversely to the generally optimistic view that smart solutions will provide both economic gain (e.g., reduced capital expenditure) and social benefits (e.g., increased reliability, and reduced losses and emissions), it is demonstrated that smart solutions can introduces new trade-offs. However, smart solutions also provide increase flexibility, which can be used to balance the different cost components if properly regulated.

The proposed methodology was illustrated with 36 real UK networks, and the results highlight four key findings, namely:

1. There may be little cost trade-offs subject to business-as-usual practices.

2. The introduction of smart solutions (e.g., DR) could facilitate attractive social and capital costs mitigation, particularly if the associated trade-offs are explicitly addressed.

3. However, if the trade-offs are not properly addressed, the emergence of smart solutions may facilitate significant social benefits at the expense of limiting capital benefits.

4. The proposed methodology can facilitate the regulation of cost trade-offs.

Future work, in progress, aims at analysing the impacts of other smart solutions and in light of the regulatory context of other European countries. 


\section{ACKNOWLEDGMENTS}

The authors are grateful to Paul Turner and Dr Rita Shaw from ENWL for the continuous support and feedback provided during the project, as well as to Angeliki Lydia Antonia Syrri and David Clements from The University of Manchester for their valuable inputs to this work.

\section{REFERENCES}

[1] Pearson, P., Watson, J., 2012. UK energy policy 1980 - 2010 A history and lessons to be learnt. IET and the Parliamentary Group for Energy Studies. Available from: <http://www.theiet.org/factfiles/energy/uk-energy-policy-page.cfm>.

[2] Shaw, R., Attree, M., Jackson, T., 2010. Developing electricity distribution networks and their regulation to support sustainable energy. Energy Policy. 38, 5927 -5937.

[3] Simmonds, G., 2002. Regulation of the UK electricity industry. University of Bath. Available from:

<http://www.bath.ac.uk/management/cri/pubpdf/industry_briefs/electricity_gillian_ simmonds.pd $>$.

[4] Navarro-Espinosa A., Mancarella, P., 2014. Probabilistic modelling and assessment of the impact of electric heat pumps on low voltage distribution networks, Applied Energy, 127, 249 -266.

[5] Ofgem, 2009. Regulating Energy Networks for the Future: RPI-X@20 History of Energy Network Regulation. Available from: < https://www.ofgem.gov.uk/ofgempublications/51984/supporting-paper-history-energy-network-regulation-final.pdf $>$.

[6] Ofgem, 2015. Smarter Markets Programme. Available from: $<$ https://www.ofgem.gov.uk/electricity/retail-market/market-review-andreform/smarter-markets-programme>.

[7] Ofgem, 2010. RIIO: A new way to regulate energy networks - Final decision. Available from: <https://www.ofgem.gov.uk/ofgem-publications/51870/decision-doc.pdf >.

[8] Ofgem, 2015. Network regulation - The RIIO model. Available from: <https://www.ofgem.gov.uk/network-regulation-\%E2\%80\%93-riio-model>.

[9] Ofgem, 2013. Template CBA RIIO ED1 v4. Available from: <cdn2.enwl.co.uk/CBA_RIIO_ED1_v4_33_kV_FFC_Cables.xlsx>.

[10] Ofgem, 2013. Strategy decision for the RIIO-ED1 electricity distribution price control: Business plans and proportionate treatment. Available from: <https://www.ofgem.gov.uk/ofgempublications/47069/riioed1decbusinessplans.pdf $>$.

[11] Ofgem, 2015. RIIO - ED1 price control. Available from: $<$ https://www.ofgem.gov.uk/network-regulation-\%E2\%80\%93-riio-model/riio-ed1price-control>. 
[12] Mancarella, P., Gan, C. K., Strbac, G., 2011. Optimal design of low voltage distribution networks for $\mathrm{CO} 2$ emission minimisation: Part I: Model formulation and circuit continuous optimisation, IET Generation Transmission and Distribution, $5,38-46$.

[13] Mancarella, P., Gan, C. K., Strbac, G., 2011. Optimal design of low voltage distribution networks for CO2 emission minimisation: Part II: Discrete optimisation of radial networks and comparison with alternative design strategies, IET Generation Transmission and Distribution, 5, 47 -56.

[14] Perrin, L.-M., 2013. Mapping power and utilities regulation in Europe, EY.

[15] Reichl J., Kollmann, A., Tichler, R., Schneider, F., 2008. The importance of incorporating reliability of supply criteria in a regulatory system of electricity distribution: An empirical analysis for Austria, Energy Policy, 36(10), 3862 -71.

[16] Schiavo, L. L., Delfanti, M., Fumagalli, E., Olivieri, V., 2013. Changing the regulation for regulating the change: Innovation-driven regulatory developments for smart grids, smart metering and e-mobility in Italy, Energy Policy, 57, 506 - 17.

[17] Broderick, J., 2015. Capacity to customers $\left(\mathrm{C}_{2} \mathrm{C}\right)$ carbon impact assessment - Final assessment report. Tyndall Manchester. Available from: < http://www.enwl.co.uk/docs/default-source/c2c-key-documents/carbon-impactassessment-report.pdf?sfvrsn=6>.

[18] Ruester, S., Schwenen, S., Batlle, C., Pérez-Arriaga, I., 2014. From distribution networks to smart distribution systems: Rethinking the regulation of European electricity DSOs, Utilities Policy, 31, 229 -37.

[19] Oskuee, M.R.J., Babazadeh, E., Najafi-Ravadanegh, S., Pourmahmoud, J., 2016. Multi-stage planning of distribution networks with application of multi-objective algorithm accompanied by DEA considering economical, environmental and technical improvements, Systems and Computers, 25 (4).

[20] Arasteh, H., Sepasian, M. S., Vahidinasab, V., 2016. An aggregated model for coordinated planning and reconfiguration of electric distribution networks, Energy, 94, $786-98$.

[21] Xing, H., Cheng, H., Zhang, Y., Zeng, P., 2016. Active distribution network expansion planning integrating dispersed energy storage systems, IET Generation, Transmission \& Distribution, 10(3), $638-44$.

[22] Ofgem, 2015. Low Carbon Network Fund. Available from: <https://www.ofgem.gov.uk/electricity/distribution-networks/networkinnovation/low-carbon-networks-fund>.

[23] ENWL, 2015. High energy users. Available from < http://www.enwl.co.uk/c2c/areyou-affected/high-energy-users $>$.

[24] Lueken, C., Carvalho, P.M.S., Apt, J., 2012. Distribution grid reconfiguration reduces power losses and helps integrate renewables. Energy Policy, 48, 260 -273.

[25] Pudjianto, D., Djapic, P., Aunedi, M., Gan, C. K., Strbac, G., Huang, S., Infield, D., 2013. Smart control for minimizing distribution network reinforcement cost due to electrification, Energy Policy. 52, 76 -84.

[26] Poudineh, R., Jamasb, T., 2014. Distributed generation, storage, demand response and energy efficiency as alternatives to grid capacity enhancements. Energy Policy. 67, $222-231$. 
[27] ENWL, 2015. Key documents. Available from: <http://www.enwl.co.uk/c2c/aboutc2c/key-documents>.

[28] Ofgem, 2012. Electricity distribution annual report for 2010-11. Available from $<$ https://www.ofgem.gov.uk/ofgempublications/46553/electricitydistributionannualreportfor201011.pdf>.

[29] Syrry, A. L. A., Mancarella, P. 2016. Reliability and Risk Assessment of Post Contingency Demand Response in Smart Distribution Networks. Sustainable Energy, Grids and Networks. In press.

[30] Zopounidis, C., Pardalos, P. M., 2010. Handbook of multicriteria analysis. Springer.

[31] Martínez Ceseña, E. A., Mancarella, P. 2016. Practical Recursive Algorithm and Flexible Open-Source Applications for Planning of Smart Distribution Networks with Demand Response. Sustainable Energy Grids and Networks. In press.

[32] Martínez Ceseña, E. A., Mancarella, P., 2014. Distribution network reinforcement planning considering demand response support. Proceedings of the Power Systems Computation Conference (PSCC) 2014, Wroclaw.

[33] Martínez Ceseña, E. A., Mancarella, P., 2014. Economic assessment of distribution network reinforcement deferral through post-contingency demand response. Innovative Smart Grid Technologies Conference Europe (ISGT-Europe), Istanbul.

[34] Syrri, A. L. A., Mancarella, P., 2014. Reliability evaluation of demand response to increase distribution network utilisation, Proceedings of the Probabilistic Methods Applied to Power Systems Conference, Durham.

[35] SP Energy Networks, 2014. SP Energy Networks 2015-2023 Business plan: Annex Cost Benefit Analysis. Available from $<$ http://www.spenergynetworks.co.uk/userfiles/file/201403_SPEN_CostBenefitAnal ysis_JW_Public.pdf>.

[36] ENWL, 2012. List of trial HV circuits. Available from: $<$ http://www.enwl.co.uk/docs/default-source/c2c-key-documents/list-of-trial-hvcircuits.pdf?sfvrsn=10>.

[37] ENWL, 2014. Capacity to Customers Project Progress Report (PPR). Available from: $<\mathrm{http} / / / \mathrm{www}$.enwl.co.uk/docs/default-source/c2c-key-documents/project-progressreport-no-6.pdf?sfvrsn=6 >.

[38] Martínez Ceseña, E. A., Mancarella, P., 2015. Sensitivity analysis of the expected economic value of the $\mathrm{C} 2 \mathrm{C}$ method. The University of Manchester. Available from:<http://www.enwl.co.uk/docs/default-source/c2c-key-documents/economicmodelling-sensitivity-analysis.pdf?sfvrsn=4>.

[39] Allan, R., Strbac, G., Djapic, P., Jarrett, K., 2013. Developing the P2/6 Methodology. UMIST. Available from:

<http://www.sedg.ac.uk/Publication/DG\%20Contribution\%20to\%20network\%20se curity_R3.pdf $>$. 